\section{Correspondence on 'Disease activity, cytokines, chemokines and the risk of incident diabetes in rheumatoid arthritis'}

We read with interest the article by Baker et al evaluating possible associations between the rheumatoid inflammatory process and the incidence of diabetes. ${ }^{1}$ In this work, many cytokines were significantly associated with the risk of diabetes, but only interleukin (IL)- $1 \alpha$ and IL- 6 were independent predictors. ${ }^{1}$ Due to the specific study design, the authors did not differentiate between type 1 diabetes (T1D) and type 2 diabetes (T2D), although the prevalence of T1D is expected to be very low, considering the mean age of involved patients. ${ }^{1}$ However, despite this limitation, these findings are of considerable interest since they furtherly reinforce the idea of a possible pathogenic loop between the rheumatoid inflammatory process and the glucose derangement, making more difficult the management of both diseases. ${ }^{2}$

In the study by Baker et al, IL- $1 \alpha$ strongly predicted the occurrence of diabetes. ${ }^{1}$ A growing body of evidence suggests the role of IL-1 family in pathogenesis of T2D, inducing to $\beta$-cell apoptosis. $^{2-4}$ Thus, IL-1 inhibition may be considered a new therapeutic strategy in improving glucose abnormalities, although conflicting results are available in the literature. ${ }^{5-9}$ A recent large randomised trial with canakinumab, a human monoclonal antibody targeting IL-1 $\beta$, did not show a significant reduction on incidence of T2D. ${ }^{5}$ Conversely, a strong improvement of glucose derangement was shown following IL-1 inhibition with anakinra, a human IL-1 receptor antagonist blocking both IL- $1 \alpha$ and IL-1 $\beta$, in patients with T2D and in those with both rheumatoid arthritis (RA) and T2D. ${ }^{67}$ In fact, a persistent reduction of glycated haemoglobin (HbA1c) was reported with anakinra in patients with T2D as well as in those with both RA and T2D. ${ }^{6-9}$ Furthermore, patients with both diseases may 'bidirectionally' benefit from anakinra, simultaneously improving both metabolic and articular inflammatory parameters. ${ }^{2}$ In a multicentre, openlabel, randomised, controlled trial, anakinra induced a significant reduction of $\mathrm{HbA} 1 \mathrm{c}$ associated with the achievement of clinical remission or minimal disease activity after 6 months of therapy in patients with RA and T2D. ${ }^{7}$ In addition, long-term findings from this study showed that the maintenance of RA remission over time was associated with glucocorticoids discontinuation, thus reducing their metabolic side effects. ${ }^{9}$ In fact, the maintenance of remission would reduce the occurrence of T2D, as it is the pivotal goal in managing the cardiometabolic risk in RA. ${ }^{10}$ Taking together these observations and the data by Baker et $a l,{ }^{1}$ a possible explanation of the different efficacy of these IL-1 inhibiting agents on T2D could be related to their specific mechanisms of action. Both IL- $1 \alpha$ and IL-1 $\beta$ may activate IL-1 type I receptor, thus inducing the inflammatory response. Anakinra, competitively inhibiting both IL- $1 \alpha$ and IL- $1 \beta$ with the binding to the cognate receptor, would fully control the IL-1 pathway. Conversely, canakinumab selectively binds IL-1 $\beta$, but it does not affect either IL- $1 \alpha$ or IL-1 receptor antagonist.

In addition, Baker et al showed that IL-6, another proinflammatory cytokine, resulted to be a significant predictor of diabetes similarly to IL- $1 \alpha{ }^{1}$ This finding confirmed previous data, showing an increased peripheral insulin resistance associated with high levels of IL- 6 and furtherly supporting the role of inflammation in glucose derangement. ${ }^{11}$ Differently, from IL-1 pathway, mainly involved at $\beta$-cell level, the action of IL- 6 seems to be more effective in peripheral tissues. IL-6 effects were studied in liver and adipose cells, relevant actors in peripheral insulin activity and resistance. ${ }^{12} 13$ IL-6 impaired insulin signalling in cultured hepatocytes, leading to inhibition of insulin-stimulated tyrosine phosphorylation of insulin receptor substrate (IRS)-1 and IRS-2 and glycogen synthesis. ${ }^{12}$ Furthermore, IL-6 inhibition enhanced the hepatic insulin sensitivity in experimental models (reviewed in Fève and Bastard). ${ }^{11}$ Similarly, chronic IL-6 stimulation induced insulin resistance in adipocytes by decreasing the transcription of IRS-1, glucose transporter type 4 and peroxisome proliferator-activated receptor $\gamma$, decreasing insulin-stimulated phosphorylation of insulin receptor IRS-1, extracellular signal-regulated kinase (ERK) 1 and ERK2 and reducing insulin-stimulated glucose transport and lipogenesis. ${ }^{13} 14$ These metabolic effects may result in increased glucose levels associated with a peripheral insulin resistance. Based on these observations and the data by Baker et al, ${ }^{1}$ a possible therapeutic strategy to improve peripheral insulin resistance by using IL- 6 inhibiting agents has been proposed in patients with RA. ${ }^{15}$

In conclusion, data deriving from the study of Baker et al may furtherly reinforce the idea of a pathogenic mutual enhancement between the rheumatoid inflammatory process and the occurrence of diabetes. ${ }^{1}$ In addition, these data may highlight the possible therapeutic role of inhibiting proinflammatory cytokines in targeting RA and associated metabolic comorbidity, counteracting a pathogenic vicious loop including glucose derangement and inflammation. Finally, in the era of precision medicine, the presence of T2D could identify a subset of patients with RA likely benefitting of specific cytokines inhibition, possibly reducing the potential failure of therapies and tailoring the medical treatment to the individual characteristics.

\section{Piero Ruscitti $\odot,{ }^{1}$ Giorgio Sesti, ${ }^{2}$ Paola Cipriani, ${ }^{1}$ Roberto Gerli $\odot,{ }^{3}$ Roberto Giacomelli ${ }^{4}$}

'Department of Clinical Sciences and Applied Biotechnology, University of L'Aquila, L'Aquila, Abruzzo, Italy

${ }^{2}$ Department of Clinical and Molecular Medicine, Sapienza University of Rome, Roma, Lazio, Italy

${ }^{3}$ Rheumatology Unit, Department of Medicine and Surgery, University of Perugia, Perugia, Italy

${ }^{4}$ Unit of Allergology, Immunology, Rheumatology, Department of Medicine, Università Campus Bio-Medico di Roma, Rome, Italy

Correspondence to Dr Piero Ruscitti, University of L'Aquila Department of Clinical Sciences and Applied Biotechnology, L'Aquila, Abruzzo, Italy; piero.ruscitti@univaq.it

Contributors All the authors meet all criteria for authorship in thelnternational Committee of Medical Journal Editors (ICMJE) Recommendations. All authors made substantial contributions to the conception or design of the work and the acquisition and interpretation of data, contributed to the critical review and revision of the manuscript, approved the final version and agreed to be accountable for all aspects of the work.

Funding The authors have not declared a specific grant for this research from any funding agency in the public, commercial or not-for-profit sectors.

\section{Competing interests None declared.}

Patient and public involvement Patients and/or the public were not involved in the design, or conduct, or reporting, or dissemination plans of this research.

Patient consent for publication Not required.

Provenance and peer review Not commissioned; internally peer reviewed.

(C) Author(s) (or their employer(s)) 2021. No commercial re-use. See rights and permissions. Published by BMJ.

\section{Check for updates}

To cite Ruscitti P, Sesti G, Cipriani P, et al. Ann Rheum Dis Epub ahead of print: [please include Day Month Year]. doi:10.1136/annrheumdis-2021-220047

Received 5 February 2021

Accepted 6 February 2021 


\section{SLinked}

http://dx.doi.org/10.1136/annrheumdis-2021-220114

Ann Rheum Dis 2021;0:1-2. doi:10.1136/annrheumdis-2021-220047

ORCID iDs

Piero Ruscitti http://orcid.org/0000-0003-3487-8551

Roberto Gerli http://orcid.org/0000-0002-4684-575X

\section{REFERENCES}

1 Baker JF, England BR, George M. Disease activity, cytokines, chemokines and the risk of incident diabetes in rheumatoid arthritis. Ann Rheum Dis 2021;72:annrheumdis-2020-219140.

2 Giacomelli R, Ruscitti P, Alvaro S, et al. IL-1 $\beta$ at the crossroad between rheumatoid arthritis and type 2 diabetes: may we kill two birds with one stone? Expert Rev Clin Immunol 2016;12:849-55.

3 Dinarello MY, Mandrup-Poulsen TCA. Targeting innate immune mediators in type 1 and type 2 diabetes. Nat Rev Immunol 2019;19:734-46.

4 Berchtold LA, Prause M, Størling J. Mandrup-Poulsen T. cytokines and pancreatic $\beta$-cell apoptosis. Adv Clin Chem 2016;75:99-158.

5 Everett BM, Donath MY, Pradhan AD, et al. Anti-Inflammatory therapy with canakinumab for the prevention and management of diabetes. J Am Coll Cardiol 2018;71:2392-401.
6 Larsen CM, Faulenbach M, Vaag A, et al. Interleukin-1-Receptor antagonist in type 2 diabetes mellitus. N Eng/ J Med 2007;356:1517-26.

7 Ruscitti P, Masedu F, Alvaro S, et al. Anti-Interleukin-1 treatment in patients with rheumatoid arthritis and type 2 diabetes (track): a multicentre, open-label, randomised controlled trial. PLoS Med 2019;16:e1002901.

8 Larsen CM, Faulenbach M, Vaag A, et al. Sustained effects of interleukin-1 receptor antagonist treatment in type 2 diabetes. Diabetes Care 2009;32:1663-8.

9 Ruscitti P, Berardicurti O, Cipriani P. On behalf of track Study Group. benefits of anakinra versus TNF inhibitors in rheumatoid arthritis and type 2 diabetes: long-term findings from participants furtherly followed-up in track study, a multicentre, openlabel, randomised, controlled trial. Clin Exp Rheumatol 2021.

10 Ruscitti P, Cipriani P, Liakouli V. Occurrence and predictive factors of high blood pressure, type 2 diabetes, and metabolic syndrome in rheumatoid arthritis: findings from a 3-year, multicentre, prospective, observational study. Clin Exp Rheumatol 2020

11 Fève B, Bastard J-P. The role of interleukins in insulin resistance and type 2 diabetes mellitus. Nat Rev Endocrinol 2009;5:305-11.

12 Senn JJ, Klover PJ, Nowak IA, et al. Interleukin-6 induces cellular insulin resistance in hepatocytes. Diabetes 2002;51:3391-9.

13 Lagathu C, Bastard J-P, Auclair M, et al. Chronic interleukin-6 (IL-6) treatment increased IL-6 secretion and induced insulin resistance in adipocyte: prevention by rosiglitazone. Biochem Biophys Res Commun 2003;311:372-9.

14 Rotter V, Nagaev I, Smith U. Interleukin-6 (IL-6) induces insulin resistance in 3T3-L1 adipocytes and is, like IL-8 and tumor necrosis factor- $\alpha$, overexpressed in human fat cells from insulin-resistant subjects. J Biol Chem 2003:278:45777-84.

15 Ursini F, Russo E, Ruscitti P, et al. The effect of non-TNF-targeted biologics and small molecules on insulin resistance in inflammatory arthritis. Autoimmun Rev 2018;17:399-404. 